\title{
Research Concerning the Influence of Balancing the Conventional Pumping Units on their Dynamics
}

\author{
DORIN BADOIU* \\ Petroleum-Gas University of Ploiesti, 39 Bucuresti Blvd., 100680, Ploiesti, Romania
}

\begin{abstract}
The paper analyses the influence of the rotary balancing and of the combined balancing (rotary and oscillating) on the variation of the motor torque at the crankshaft and on the variation of the connection forces acting in the joints of the mechanism of the conventional pumping units. For this purpose a computer program has been developed and a series of results in the case of a C-640D-305120 pumping unit are presented.
\end{abstract}

Keywords: pumping unit, rotary and combined balancing, motor torque, connecting forces

\section{Introduction}

It is well known that for a good functioning of the sucker rod pumping installations the pumping units from their component must be correctly balanced. Balancing the pumping units represents the operation by which it is followed that the maximum values of the motor torque at the crankshaft corresponding to the ascending and descending strokes of the sucker rod column are equal $[1,2]$. The balancing of the conventional pumping units is achieved by adding counterweights in the extension of the cranks in the case of rotary balancing or by adding counterweights both in the extension of the cranks and in the extension of the rocker in the case of combined balancing (rotary and oscillating).

In the paper is analyzed the influence of the rotary balancing and of the combined balancing on the variation of the motor torque at the crankshaft and on the variation of the connection forces acting in the joints of the mechanism of the conventional pumping units. Starting from the calculation methodology a computer program has been developed which allows performing a comparative analysis of the influence of the rotary balancing and of the combined balancing on the variation of the mentioned parameters.

\section{Materials and methods}

\subsection{Experimental part}

For establishing the values of the connection forces acting on the joints of the pumping unit mechanism and of the motor torque at the crankshaft were analyzed several records concerning the variation of the force at the polished rod in the case of a C-640D-305-120 pumping unit to check that this one is in a stable operating condition. In Figure 1 is represented such a variation curve corresponding to the stroke 85. The processing of the records was done with the Total Well Management program [3].

\subsection{Determining the connecting forces and the motor torque}

Dynamics of the sucker rod pumping installations represents a topical field of research, some significant results regarding the dynamics of the conventional pumping units and of the sucker rod column being presented in [4-10].

In Figure 2 where is presented the mechanism of a conventional pumping unit the following notations were used: $m_{C G 1}$ is the mass of the counterweights mounted on the cranks; $m_{C G 2}$ represents the mass of the counterweights mounted on the extension of the rocker; $M_{m}$ is the motor torque at the crankshaft and $\bar{F}$ is the force at the polished rod.

\footnotetext{
*email:dorin.badoiu@gmail.com
} 


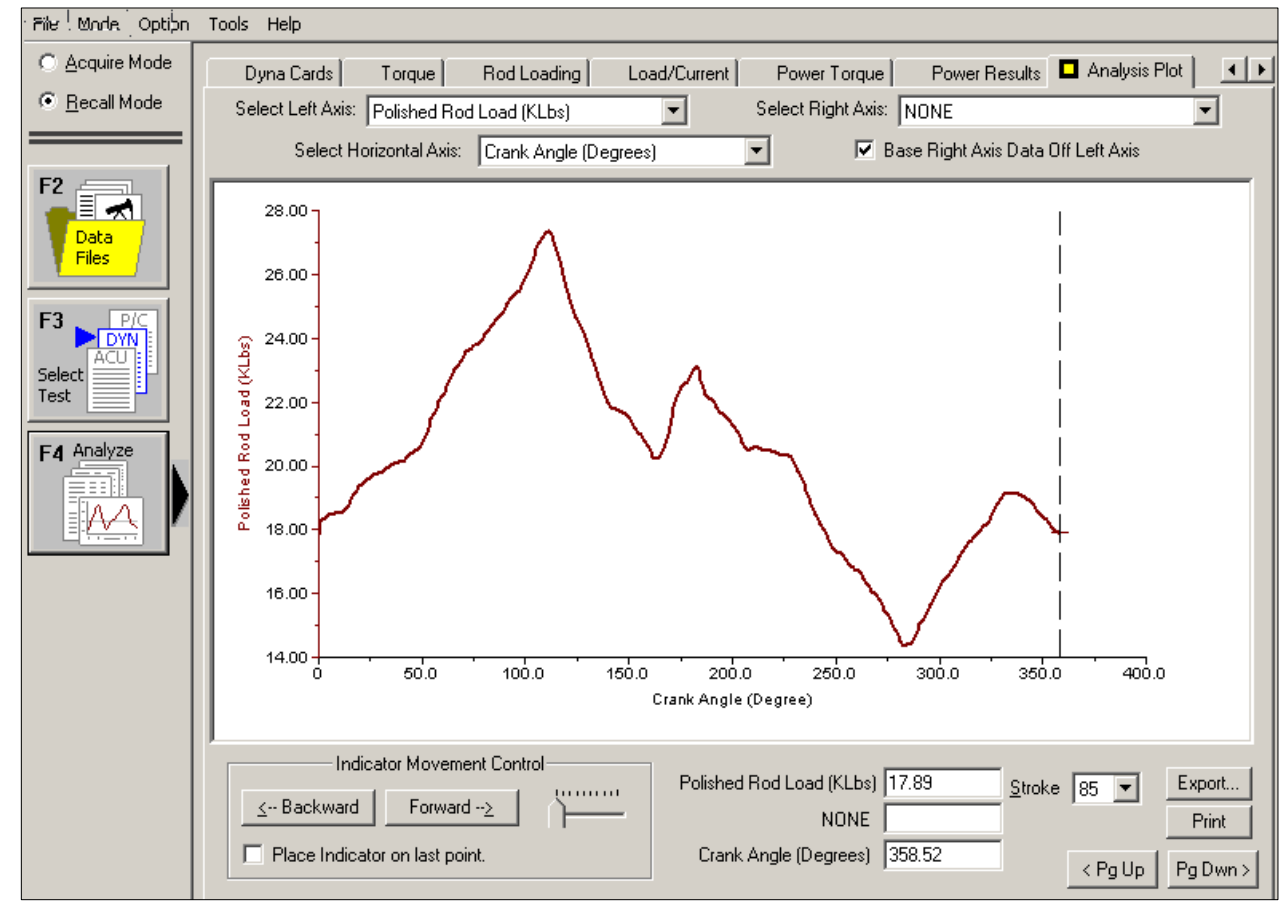

Figure 1. The variation curve during the stroke 85 of the force at the polished rod

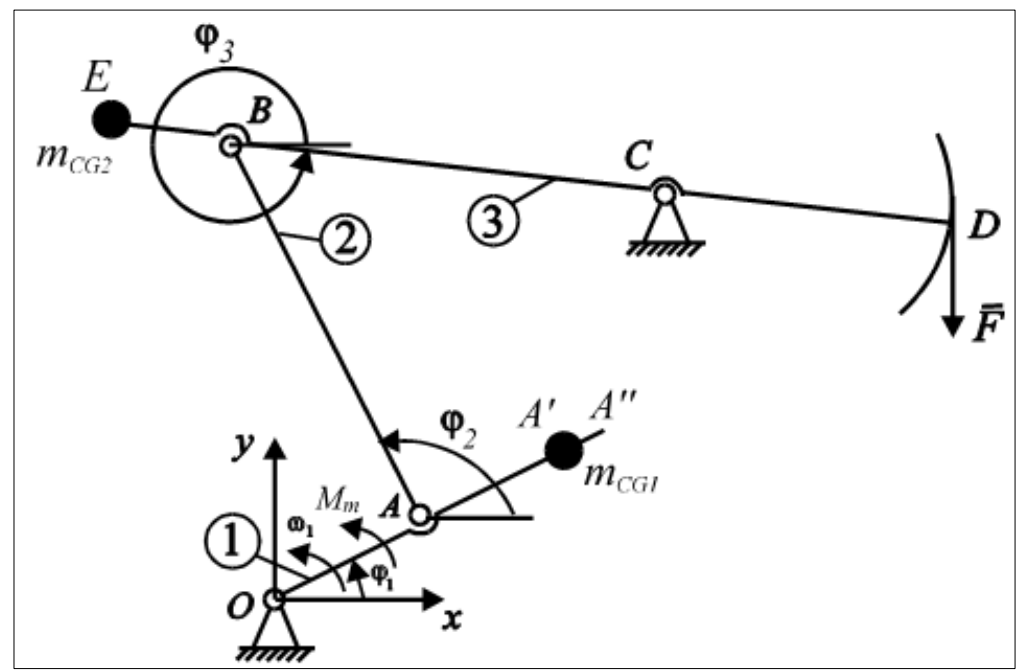

Figure 2. The cinematic scheme of a conventional pumping unit mechanism

In Figure 3 and Figure 4 were represented the load schemes of the connecting rods and the rocker, which make up dyad (2-3) and of the cranks. $\bar{G}_{1}, \bar{G}_{2}$ and $\bar{G}_{3}$ are the weight forces of the two cranks, of the two connecting rods and of the rocker, respectively; $\bar{G}_{C G 1}$ and $\bar{G}_{C G 2}$ are the weight forces of the counterweights mounted on the cranks and on the rocker, respectively. Also, in Figure 3 and Figure 4 were represented the projections of the connection forces acting in the component bearings: $2 \bar{F}_{12}$ from the two crank pin bearings acting on the connecting rods and $2 \bar{F}_{21}=-2 \bar{F}_{12}$ acting on the cranks; $2 \bar{F}_{01}$ from the two joints connecting the two cranks and the output shaft of the reducer; $\bar{F}_{03}$ from the centre bearing.

Because the pumping units mechanism is very slow and in the case of a normal operation the shocks or vibrations that appear are very low, in the performed calculations the forces and the moments of inertia were neglected. 


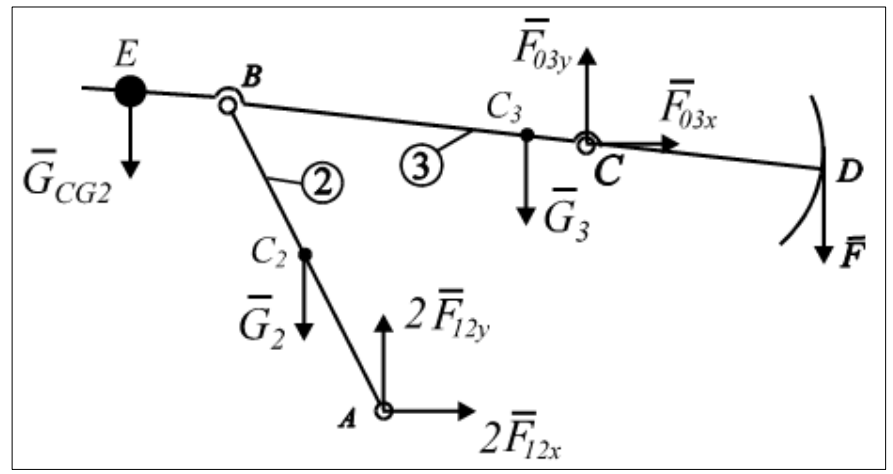

Figure 3. Representation of loads on connecting rods and rocker

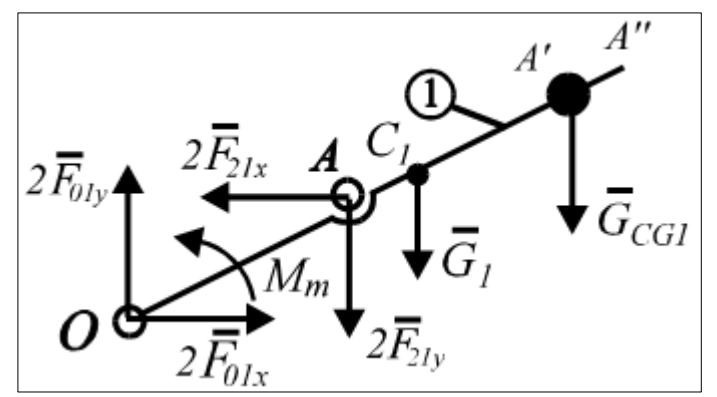

Figure 4. Representation of loads on cranks

From writing the equilibrium equations in forces in the case of the dyad (2-3) (Figure 3), it results:

$$
\left\{\begin{array}{l}
2 F_{12 x}+F_{03 x}=0 \\
2 F_{12 y}+F_{03 y}-G_{2}-G_{C G 2}-G_{3}-F=0
\end{array}\right.
$$

From the equation of equilibrium in moments on the whole dyad in relation to point $A$ (Figure 3 ), it results:

$$
\begin{aligned}
& \left(x_{C}-x_{A}\right) \cdot F_{03 y}-\left(y_{C}-y_{A}\right) \cdot F_{03 x}-\left(x_{D}-x_{A}\right) \cdot F-\left(x_{C_{3}}-x_{A}\right) \cdot G_{3}- \\
& -\left(x_{E}-x_{A}\right) \cdot G_{C G 2}-\left(x_{C_{2}}-x_{A}\right) \cdot G_{2}=0
\end{aligned}
$$

Considering only the component 2 of the dyad (Figure 3 ), from the equilibrium equation in moments in relation to point $B$ results:

$$
2 \cdot\left(x_{A}-x_{B}\right) \cdot F_{12 y}-2 \cdot\left(y_{A}-y_{B}\right) \cdot F_{12 x}-\left(x_{C_{2}}-x_{B}\right) \cdot G_{2}=0
$$

From the equilibrium equations in forces on the directions of the $x$ and $y$ axes in the case of the cranks (Figure 4 ) by considering that: $2 \bar{F}_{21}=-2 \bar{F}_{12}$, it results:

$$
\left\{\begin{array}{l}
2 F_{01 x}-2 F_{12 x}=0 \\
2 F_{01 y}-2 F_{12 y}-G_{1}-G_{C G 1}=0
\end{array}\right.
$$

Then, from the equilibrium equation in moments in relation to point $O$ (Figure 4) results:

$$
M_{m}-2 \cdot x_{A} \cdot F_{12 y}+2 \cdot y_{A} \cdot F_{12 x}-x_{C_{1}} \cdot G_{1}-x_{A^{\prime}} \cdot G_{C G 1}=0
$$

From resolving the system composed of the equations $1 \div 5$ it results: $F_{03 x}, F_{03 y}, F_{12 x}, F_{12 y}, F_{01 x}, F_{01 y}$, and the motor torque $\mathrm{M}_{\mathrm{m}}$.

For determining the connection force from the equalizer bearing $\bar{F}_{23}$ (Figure 5) were used the following equilibrium equations in forces: 


$$
\left\{\begin{array}{l}
F_{23 x}+F_{03 x}=0 \\
F_{23 y}+F_{03 y}-G_{3}-G_{C G 2}-F=0
\end{array}\right.
$$

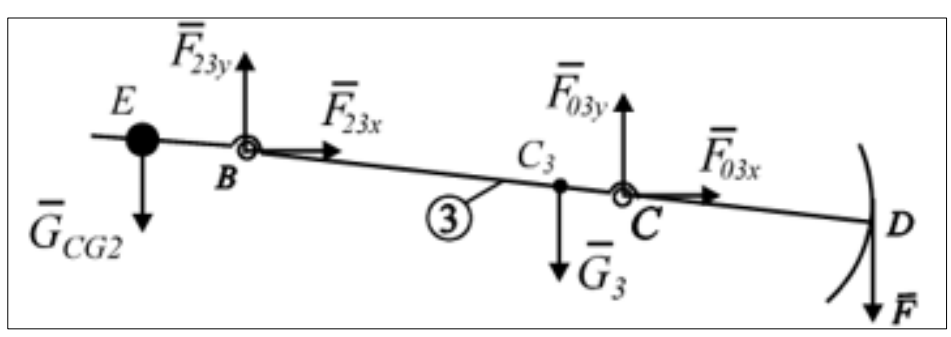

Figure 5. Load scheme of the rocker

The coordinates of the different points that appear in the equations of equilibrium 2,3 and 5 are determined following the positional analysis of the pumping units mechanism [11-13]. For this, the method of projection of closed and independent vector contours can be used [14,15].

The vector equation: $\overline{O A}+\overline{A B}+\overline{B C}+\overline{C O}=0$ (Figure 2) projected on $x$ and $y$ axes leads to obtaining the following system of equations:

$$
\left\{\begin{array}{l}
O A \cdot \cos \varphi_{1}+A B \cdot \cos \varphi_{2}+B C \cdot \cos \varphi_{3}-x_{C}=0 \\
O A \cdot \sin \varphi_{1}+A B \cdot \sin \varphi_{2}+B C \cdot \sin \varphi_{3}-y_{C}=0
\end{array}\right.
$$

Solving this system of equations it results the angles $\varphi_{2}$ and $\varphi_{3}$, and then knowing these angles we can determine the coordinates of any point on the mechanism of the pumping unit.

\section{Results and discussions}

Starting from the calculation methodology presented a computer program has been developed using Maple programming environment. It is presented below a series of results of the simulations realized in the case of a pumping installation serviced by a C-640D-305-120 pumping unit produced by Lufkin [17] for which are known: $O A=0.762 \mathrm{~m} ; A B=3.391 \mathrm{~m} ; B C=2.822 \mathrm{~m} ; C D=3.937 \mathrm{~m} ; O A^{\prime \prime}=2.413 \mathrm{~m}$; $x_{C}=2.819 \mathrm{~m}$ and $y_{C}=3.505 \mathrm{~m}$.

The values of the crank angles corresponding to the beginning of the ascending and descending strokes of the sucker rod column are: $88.976^{\circ}$ and $266.929^{\circ}$, respectively. A way to calculate these angles is presented in [16].

The linear masses of the cranks, connecting rods and of the rocker, denoted with: $q_{1}, q_{2}$ and $q_{3}$, respectively, have the following values: $\mathrm{q}_{1}=722 \mathrm{~kg} / \mathrm{m} ; \mathrm{q}_{2}=34 \mathrm{~kg} / \mathrm{m} ; \mathrm{q}_{3}=300 \mathrm{~kg} / \mathrm{m}$.

The working angular speed of the cranks is: $6.6 \mathrm{rot} / \mathrm{min}$.

The simulations were performed considering the two balancing cases: rotary and combined (rotary and oscillating). For the case of rotary balancing it was considered that the counterweights of total mass equal to $4808 \mathrm{~kg}$ are mounted on the cranks so that $O A^{\prime}=1.6 \mathrm{~m}$ (Figure 2). In the case of combined balancing it was considered that the counterweights mounted on the cranks are of total mass equal to $2404 \mathrm{~kg}$ and $O A^{\prime}=2.032 \mathrm{~m}$ and the counterweights mounted on the rocker are of total mass equal to $2500 \mathrm{~kg}$ and $B E=1.05 \mathrm{~m}$ (Figure 2).

In the following figures are represented the variations on a cinematic cycle beginning with the angle corresponding to the beginning of the ascending stroke of the sucker rod column of the values of the connection forces: $F_{01}, F_{12}, F_{23}, F_{03}$ and of the motor moment $M_{m}$ by considering the variation of the force at the polished rod during the stroke 85 (Figure 1). The curves denoted with 1 correspond to the case of combined balancing and the curves denoted with 2 correspond to the case of rotary balancing. 


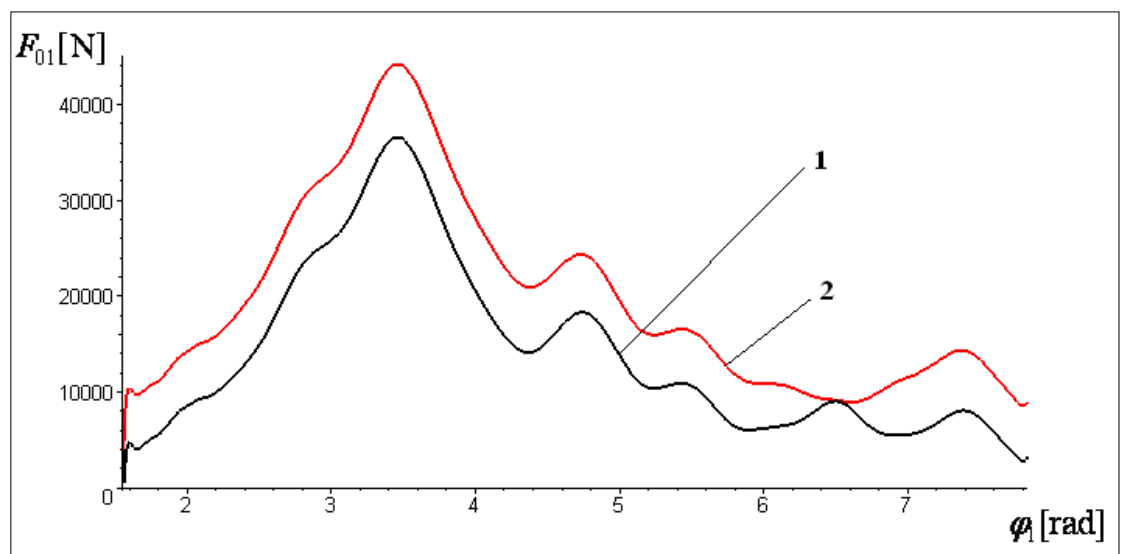

Figure 6. The variation of the connecting force $\mathrm{F}_{01}$ (1 - combined balancing; 2 - rotary balancing)

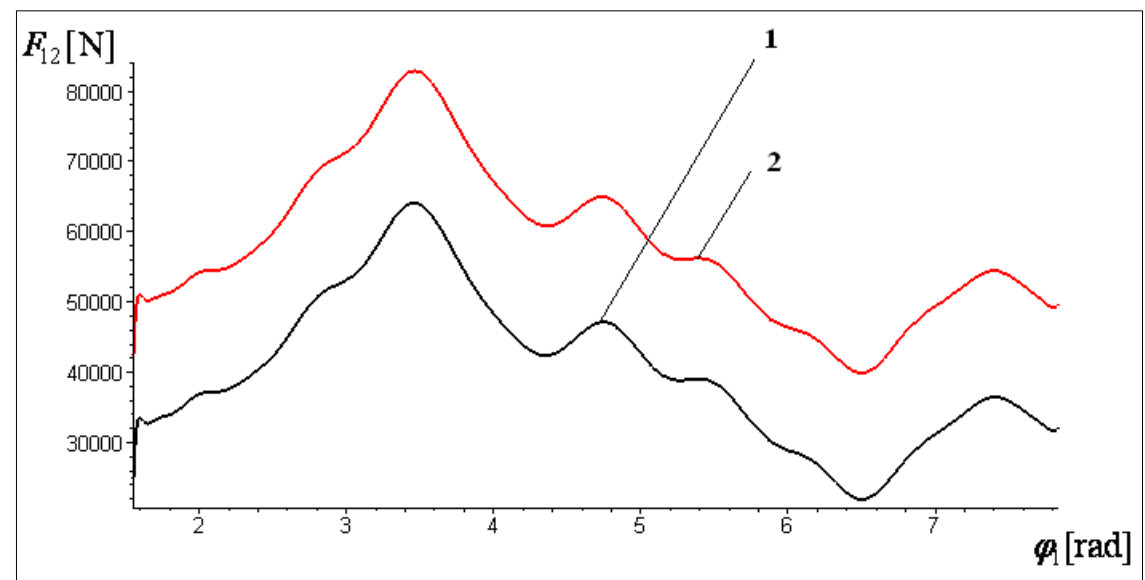

Figure 7. The variation of the connecting force $F_{12}$

(1 - combined balancing; 2 - rotary balancing)

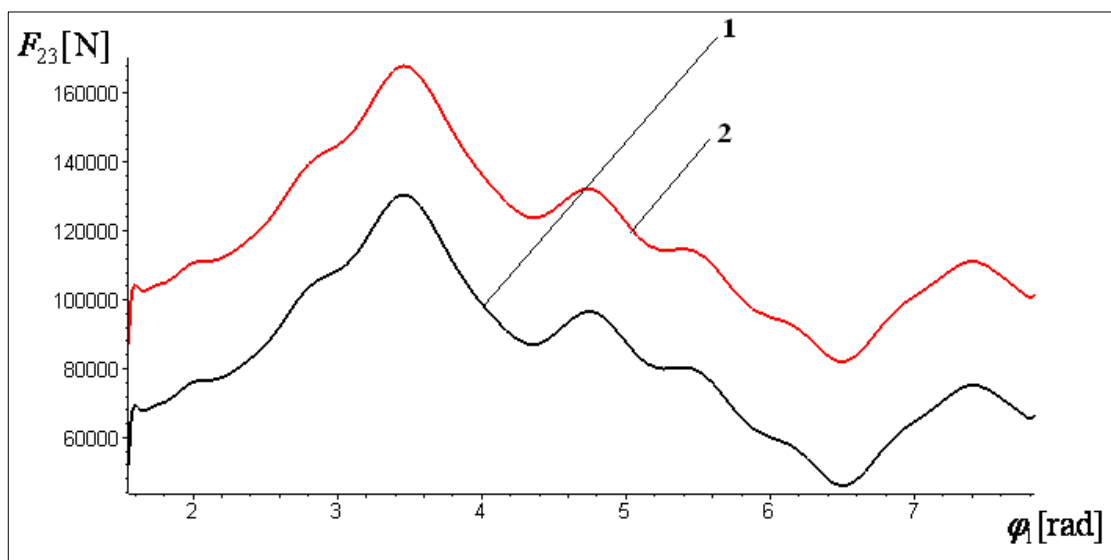

Figure 8. The variation of the connecting force $F_{23}$

(1 - combined balancing; 2 - rotary balancing) 


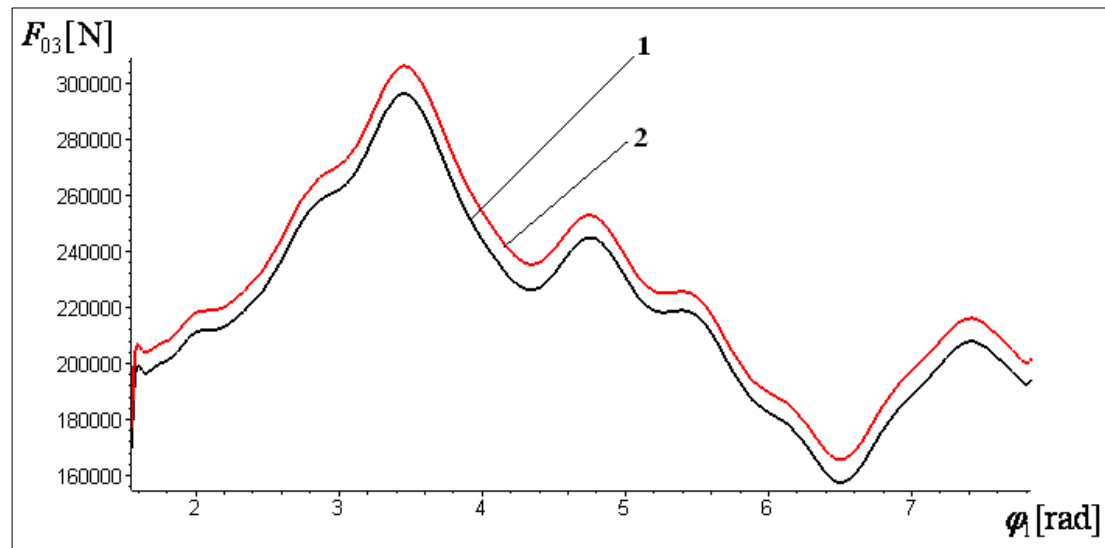

Figure 9. The variation of the connecting force $\mathrm{F}_{03}$

(1 - combined balancing; 2 - rotary balancing)

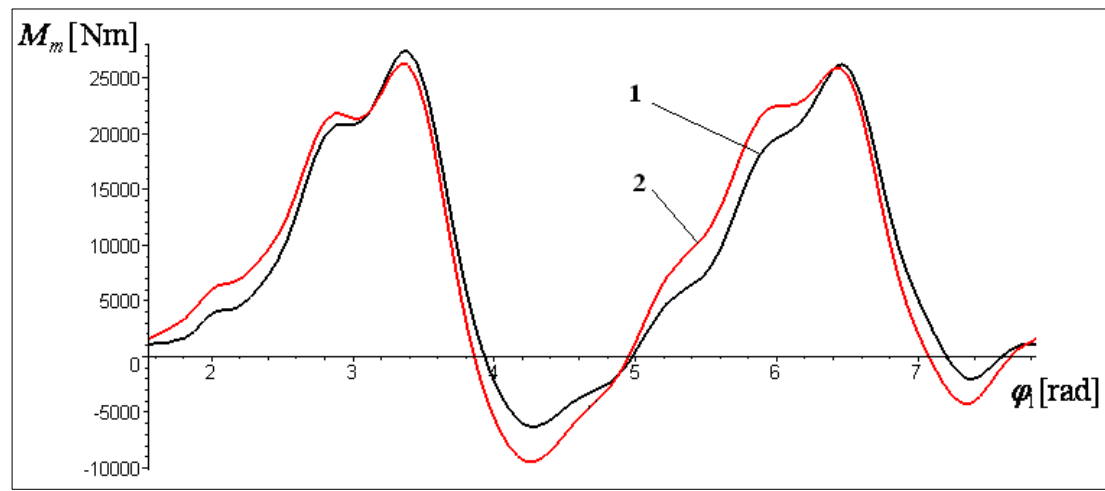

Figure 10. The variation of the motor torque $M_{m}$

(1 - combined balancing; 2 - rotary balancing)

Figure 10 shows that the maximum values of the motor torque $M_{m}$ corresponding to the ascending and descending strokes of the sucker rod column are very close, which shows that both balancing possibilities (rotary and combined) lead to a correct operation of the pumping installation. Moreover, the balancing solutions proposed for the analysis lead to close values of the motor torque $M_{m}$, with the observation that in the case of combined balancing there is a distribution of the mass of the counterweights on the structure of the pumping unit mechanism. This distribution of the mass of the counterweights leads to obtaining lower loads of the joints of the pumping unit as can be seen in Figures $6 \div 9$.

\section{Conclusions}

In the paper has been analyzed the mechanism of conventional pumping units for determining the motor torque at the crankshaft and the connecting forces acting in the component joints. The simulation program developed using Maple programming environment allowed performing a comparative analysis of the influence of the rotary balancing and of the combined balancing on the variation of the motor torque at the crankshaft and on the variation of the connection forces acting in the joints. The obtained results highlighted that both balancing possibilities (rotary and combined) lead to a correct operation of the pumping installation, but the distribution of the mass of the counterweights corresponding the combined balancing leads to obtaining lower loads of the bearings of the pumping unit. 


\section{References}

1.GIBBS, S.G., Computing gearbox torque and motor loading for beam pumping units with consideration of inertia effects, J. Pet. Technol., 1975 (September), p. 1153-1159.

2. POPOVICI, A., Utilaj pentru exploatarea sondelor de petrol (Equipment for the exploitation of the oil wells), Editura Tehnica, Bucuresti, 1989, p. 55-75.

3.***Echometer Total Well Management (TWM),

https://www.echometer.com/Software/Total-Well-Management, (accessed on 26 August 2020).

4. BADOIU, D., TOMA, G., Research concerning the identification of some parameters of a sucker rod pumping unit, Rev. Chim., 68(10), 2017, 2289-2292.

5. BADOIU, D., TOMA, G., Research concerning the kinetostatic analysis of the mechanism of the conventional sucker rod pumping units, Rev. Chim., 69(7), 2018, 1855-1859.

6. BADOIU, D., TOMA, G., Research concerning the predictive evaluation of the motor moment at the crankshaft of the conventional sucker rod pumping units, Rev. Chim., 70(2), 2019, 378-381.

7. BADOIU, D., TOMA, G., Analysis of the dynamic response of the mechanism of conventional sucker rod pumping units, Rev. Chim., 71(1), 2020, 395-399

8. TOMA, G., PUPAZESCU, A., BADOIU, D., Simulation of the Sucker Rod Column Dynamics for Different Pumping Regimes, Rev. Chim., 68(11), 2017, 2593-2596.

9. TOMA, G., BADOIU, D., Research concerning the influence of some constructive errors on the dynamics of a pumping unit, Petroleum-Gas University of Ploiesti Bulletin, Technical Series, 63(4), 2011, p. 27-30.

10. BADOIU, D., TOMA, G., On a dynamic optimisation problem of the quadrilateral mechanism, Journal of the Balkan Tribological Association, 22(1), 2016, p. 250-260.

11. BADOIU, D., TOMA, G., Research concerning the correlations between some experimental results in the case of a sucker rod pumping installation, Rev. Chim., 69(11), 2018, 3060-3063.

12. TOMA, G., BADOIU, D., On the cinematic analysis of a mechanism of fourth class, Petroleum-Gas University of Ploiesti Bulletin, Technical Series, 64(1), 2012, p. 69-72.

13. TOMA, G., BADOIU, D., Research concerning the calculus of the equilibrium moment in the case of a plane mechanism using the dynamic model, Petroleum-Gas University of Ploiesti Bulletin, Technical Series, 67(2), 2015, p. 93-98.

14. BADOIU, D., TOMA, G., Research on designing a multiloop planar linkage, IOP Conference Series: Materials Science and Engineering, 659(1), 2019, p. 1-7.

15. BADOIU, D., TOMA, G., Structura si cinematica mecanismelor cu bare (The structure and the kinematics of the mechanisms with bars), Ed. Universitatii Petrol-Gaze din Ploiesti, 2019, p. 178-199.

16. TOMA, G., PUPAZESCU, A., BADOIU, D., On a synthesis problem of the mechanism of a sucker rod pumping unit, Petroleum-Gas University of Ploiesti Bulletin, Technical Series, 65(4), 2013, p. 107 111.

17.*** Pumping unit general catalog oilfield products group,

https://docplayer.net/78869533-Pumping-unit-general-catalog-oilfield-products-group.html, (accessed on 26 August 2020).

Manuscript received: 01.09.2020 